\title{
Study of Sound Absorption Characteristics of Pavement Materials
}

\author{
L.J. Chu and T. F. Fwa
}

\begin{abstract}
Traffic noise is a major form of environmental noise pollution today in most densely populated urban areas. The noise generated from motor engines, transmission and exhaust systems of modern vehicles has been very much reduced due to various advancements in design technologies of modern automobile industry. On most highways today, tire-pavement noise has become the dominating source of traffic noise where traffic speeds is higher than about $45 \mathrm{~km} / \mathrm{h}$. The conventional dense graded asphalt pavements and portland cement concrete pavements often generate high traffic noise, and are considered to be undesirable from the consideration of traffic noise reduction. Major research and development efforts are on-going globally in search of ways in which tire-pavement noise could be reduced. One major component of tire-pavement noise is the noise reflected from the pavement surface. This is related to the sound absorption properties of pavement materials. This study examines the sound absorption characteristics of common road making materials with the aim to identify those material properties that could be changed during the pavement design phase so as to reduce tire-pavement noise. The common forms of asphalt and Portland cement concrete pavement materials are examined, along with widely used designs of porous asphalt and pervious concrete materials. Experiments were also performed to study the factors that affect the long-term noise reduction properties of the various pavement materials examined.
\end{abstract}

Index Terms - asphalt pavement, Portland cement concrete pavement, sound absorption characteristics, traffic noise.

\section{INTRODUCTION}

$\mathbf{T}$ oday traffic noise is a major form of environmental noise pollution in most densely populated urban areas. The noise generated from motor engines, transmission and exhaust systems of modern vehicles has been very much reduced due to various advancements in design technologies of modern automobile industry.

\footnotetext{
L.J. Chu is with the School of Highway, Chang'an University, 710064, Xi'an, China (e-mail: longjiachu@chd.edu.cn)

T.F. Fwa is with the School of Highway, Chang'an University, 710064, Xi'an, China
}

In comparison, tire -pavement noise has become a key source of traffic noise. The application of porous pavements has attracted more and more attention due to its two significant benefits, i.e. reduction of tire-pavement noise and improvement of wet weather safety. However, a major issue attracting serious concern is that porous pavements are prone to be clogged up which will reduce the effectiveness of their sound absorption capability. It has been recognized by past researchers that the service life for porous pavements is largely dependent on the clogging of the porous mixtures [1]. Thus, it is of great interest to know how the choice of different porous pavement mixes will affect their clogging performance during the whole service life.

The main objective for this study is to evaluate the effect of one of the most important parameters of porous pavements, namely their porosity levels, on the effectiveness of their sound absorption capability. Four different pavement wearing course materials were studied: PC mixtures with different porosity level, PA mixtures with different porosity level, a DG (Dense Graded) asphalt mixture and an NC (Normal Concrete) mixture for reference. Target porosity of PA (Porous Asphalt) and PC (Porous Concrete) mixtures included 10\%, 15\%, 20\% and $25 \%$. The clogging state started from $0 \%$ to $100 \%$, $0 \%, 25 \%, 50 \%, 75 \%$ and $100 \%$ specifically.

\section{EXPERIMENTAL PROGRAM}

\section{A. Preparation of Test Specimens}

For each test mixture, three duplicate specimens were prepared. For each porosity level, the set of three test specimens were first tested for their permeability and sound absorption coefficient at the initial unclogged state. Next, by applying clogging treatment in stages, the permeability and sound absorption coefficient at each successive clogged state were measured, until the fully clogged stage was reached. The test procedure for the sound absorption measurements of clogged and unclogged specimens is shown in Fig. 1.

Table I and Fig. 2 show the aggregate gradations for PC and PA mixtures. The ASTM Type I ordinary Portland cement was used when fabricating PC and NC specimens. The coarse aggregate used was natural crushed granite in the range from 9.5 to $1.18 \mathrm{~mm}$ following the grading requirements of ASTM C33/ C33M-13 Size number 89. 
TABLE I

MIX PROPORTION FOR PC DESIGNS ADOPTED IN STUDY

\begin{tabular}{cc}
\hline Sieve Size & Percentage Passing \\
\hline $12.5 \mathrm{~mm}$ & 100 \\
$9.5 \mathrm{~mm}$ & 95 \\
$4.75 \mathrm{~mm}$ & 38 \\
$2.36 \mathrm{~mm}$ & 18 \\
$1.18 \mathrm{~mm}$ & 5 \\
$300 \mu \mathrm{m}$ & 3 \\
\hline
\end{tabular}

\section{B. Clogging Treatment}

Clogging is a common distress form that would severely reduce the effectiveness of sound absorption capability. Clogging behavior for different mix designs were studied by bringing a preselected clogging agent to the internal structure of mixtures studied to reach different clogging stages, starting from the initial unclogged stage to the final fully clogged stage. Residual soil was used as clogging agent in this study. The gradation for the residual soil selected was $100 \%$ passing $1.18 \mathrm{~mm}$, $94.3 \%$ passing $0.6 \mathrm{~mm}, 84.8 \%$ passing $0.3 \mathrm{~mm}$, and $58.2 \%$ passing $0.075 \mathrm{~mm}$. The experimental apparatus applied to reach different clogged stages for mixtures was constant-head apparatus [1] [2]. In the process of clogging, 5.3g of residual soil was spread on the top of the test specimen at the beginning of each clogging stage and was brought to the internal structure of test specimen under a constant-head flow.

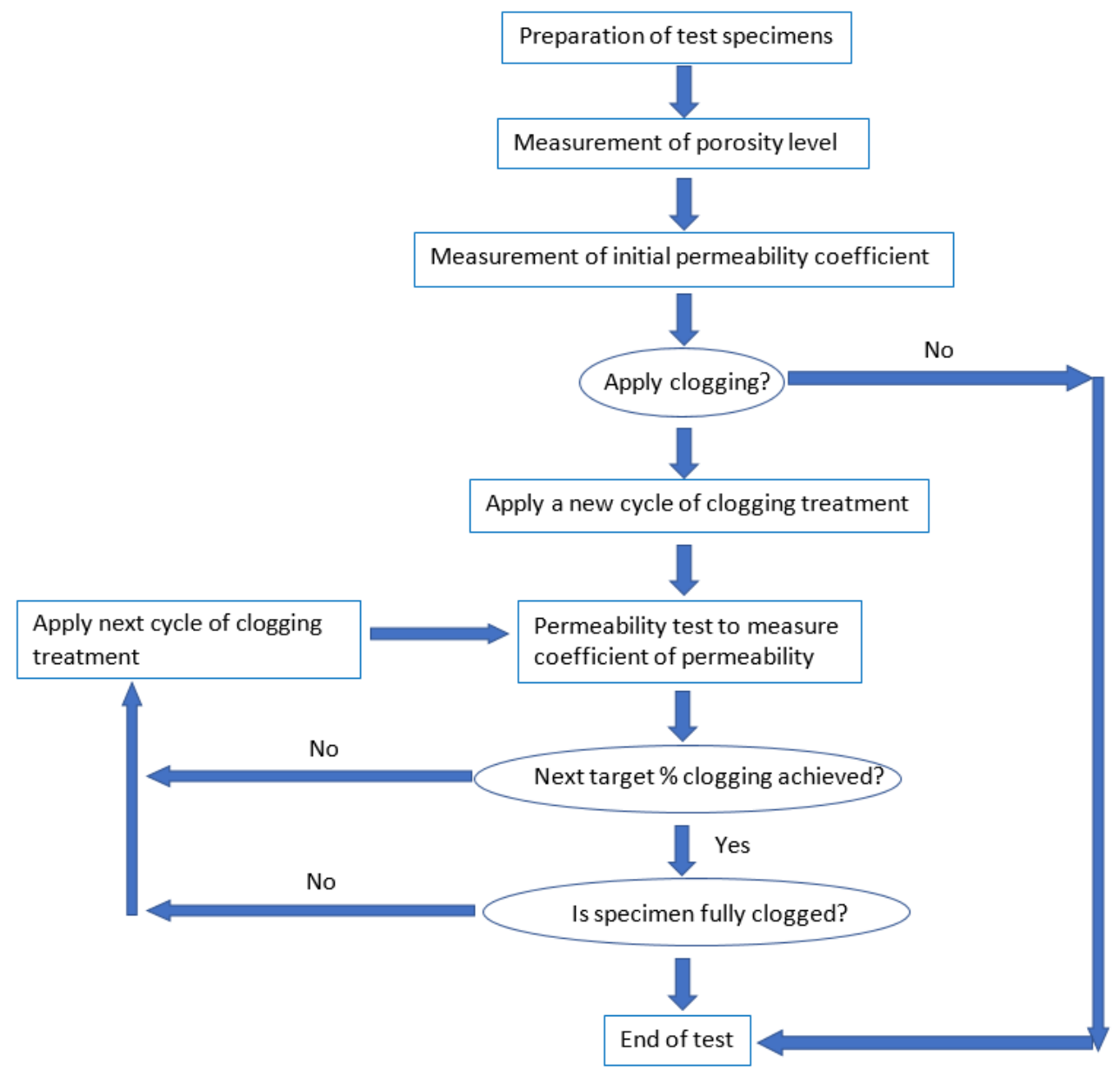

Fig.1. Flow Diagram of Experimental Test Procedure

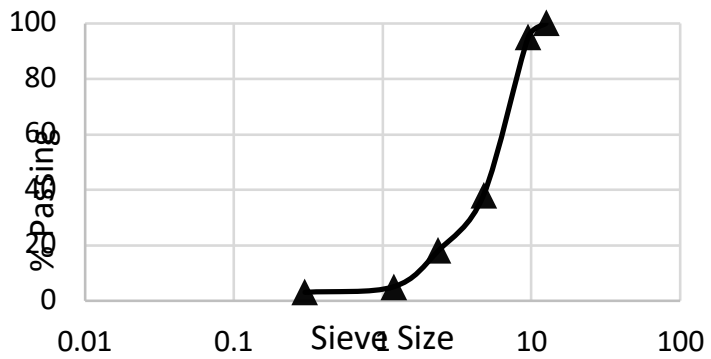

Fig. 2. Aggregate Gradation of PA Mixes Studied

C. Permeability Measurements
Porosity level is equal to the percet air voids of porous mixtures. There are two key parameters to express the clogged stage of a porous mixture, namely permeability and porosity as shown in Equation (1) and (2): $\%$ clogged based on porosity $=\left[1-\frac{\text { Porosity after clogging }}{\text { Porosity before clogging }}\right] \times 100 \%$

(1)

$\%$ clogged based on permeability $=\left[1-\frac{\text { Permeability coefficient after clogging }}{\text { Permeability coefficient before clogging }}\right] \times 100 \%$ (2) 
Equation (2) is considered to be more practical than Equation (1) due to following two main reasons:

(1) It is much easier to perform permeability measurements compared with porosity measurements.

(2) The test apparatus developed by the author permits non-destructive measurements of permeability to be made both in the field and in the laboratory.

To express the permeability coefficient of porous pavement, past research studies have proved that the following equation is applicable to compute the permeability coefficient of porous pavement [3] [4]:

$$
k=\frac{v}{i^{n}}
$$

where $\mathrm{k}$ is the permeability coefficient, $\mathrm{v}$ the flow velocity, $\mathrm{i}$ the hydraulic gradient, and $\mathrm{n}$ a numerical constant. Based on this theory, the apparatus developed by the author is capable of measuring the permeability either in the field or in the laboratory within 1 to 2 minutes. The measurements of permeability of porous pavements were carried out using the method of falling-head mode.

\section{Acoustic Absorption Measurements}

The ASTM E1050-10 standard procedure was followed to measure the sound absorption coefficient of all test specimens. The standing wave method was applied to conduct the sound absorption coefficient measurements. In the process, one loudspeaker was used to generate a plane sound wave from one end of the tube and the sound wave was terminated by the specimen installed one the other end of the tube. By measuring the ratio between the maximum and minimum sound pressures, the sound absorption coefficient can be calculated accordingly.

The frequency range from 100 to $2500 \mathrm{~Hz}$ was selected to conduct sound absorption coefficient measurements in this study. This selected range was broad enough to cover the frequency range of 630 to $2000 \mathrm{~Hz}$ which was found to be significant to human beings [5] [6]. When the frequency range was lower than $500 \mathrm{~Hz}$, a $100 \mathrm{~mm}$ diameter impedance tube was adopted to measure the sound absorption coefficient of test specimens; while a $29 \mathrm{~mm}$ diameter impedance tube was used when the frequency range was higher than $500 \mathrm{~Hz}$, in accordance with the ASTM E1050-10 standard procedure.

\section{LABORATORY TEST RESUltS}

\section{A. Effect of Porosity Levels on Sound Absorption Property}

The results of acoustic absorption measurements for different tested specimens, including four PC mix designs PC-10, PC-15, PC20, and PC-25, four PA mix designs PA-13, PA-16, PA20, and PA-25, as well as the reference NC and DG asphalt are plotted in Fig. 3. The measured sound absorption coefficient at one-third octave frequencies are shown in this figure. For better comparison between $\mathrm{PC}$ and $\mathrm{PA}$ mix designs at comparable porosity levels, Fig. 4 gives pairwise plots of sound absorption coefficient of PC and PA mix designs under the same porosity levels.

Based on these results, the following conclusions can be made:

(1) At comparable porosity levels, PC mix designs possessed better sound absorption capability than PA mix designs. The same conclusion can be made between DG and NC mixtures.

(2) The improvements of sound absorption capability for both PA and PC mix designs over the $\mathrm{NC}$ and DG asphalt were most significant within the frequency range of 250 to $1,250 \mathrm{~Hz}$.

(3) As the porosity level of either PA or PC mixtures decreased, there was a tendency for the peak sound absorption range to move toward the lower frequency end.

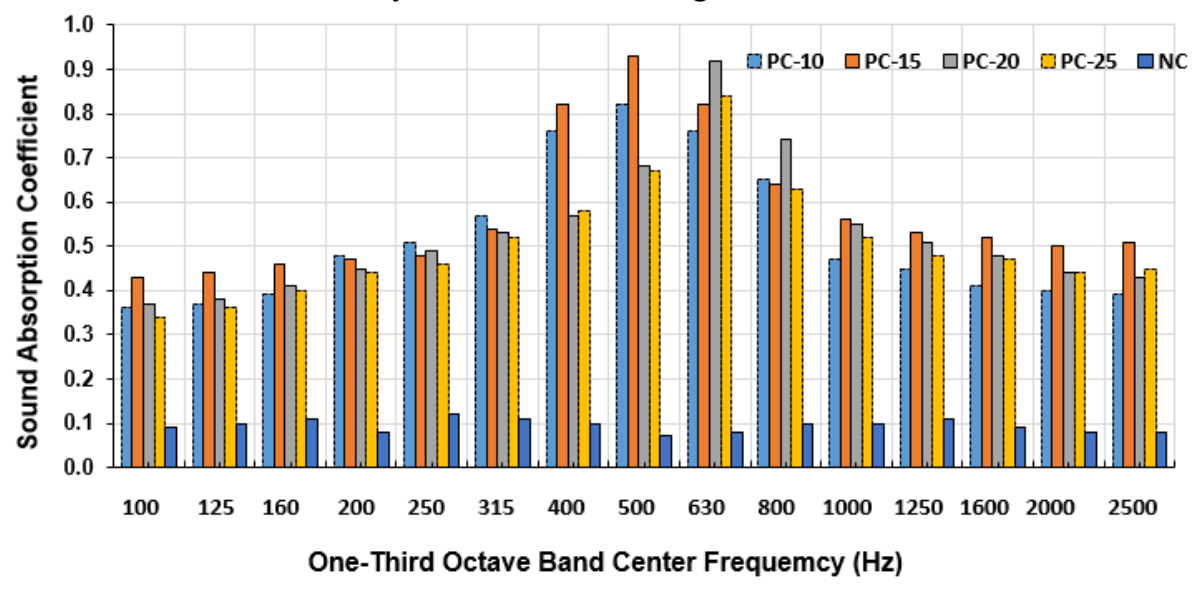




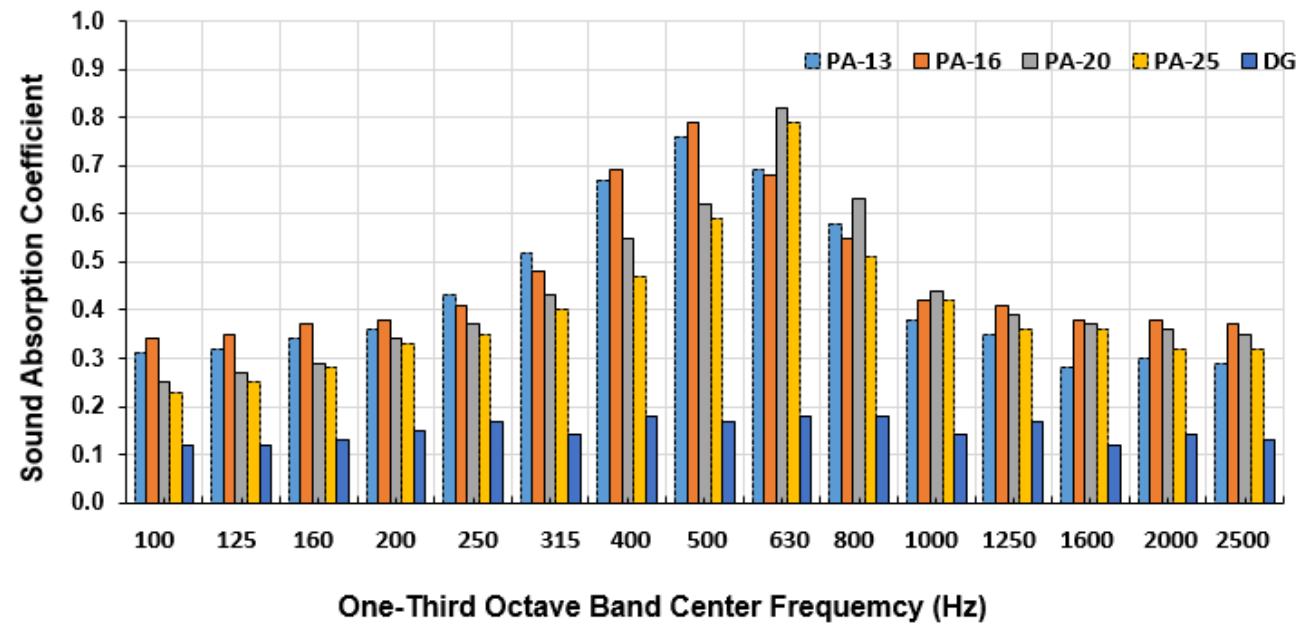

(b)

Fig. 3 Measured sound absorption spectra of (a) PC and NC and (b) PA and DG asphalt

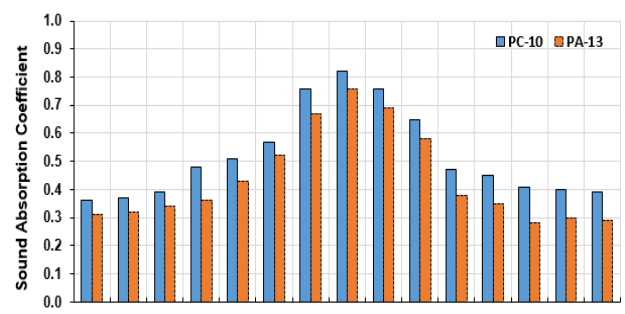

One-Third Octave Band Center Frequemcy (Hz)
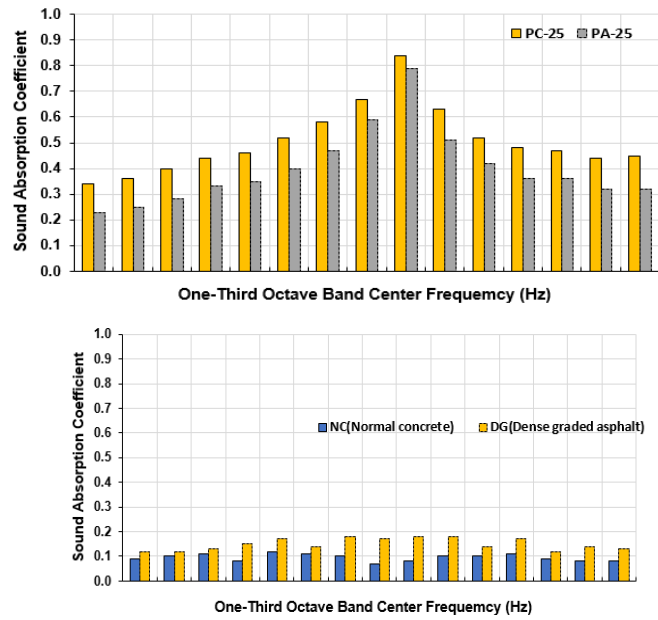

Fig. 4 Sound absorption spectra of test materials at different porosity levels

$B$ Effect of Clogging on Sound Absorption Property

The clogging effect of sound absorption capability were plotted in Fig. 6 for the five target clogging state studied in this research, namely $0 \%$, $25 \%, 50 \%, 75 \%$, and $100 \%$. From the results, it can be concluded that as the clogging percentage increased, the sound absorption capability of test specimens decreased progressively. It is interesting to note that at the fully clogged stage, the PC mixtures still presented better sound absorption capabilities than the $\mathrm{NC}$, while the PA mixtures displayed almost the same sound absorption capabilities compared with the DG. 

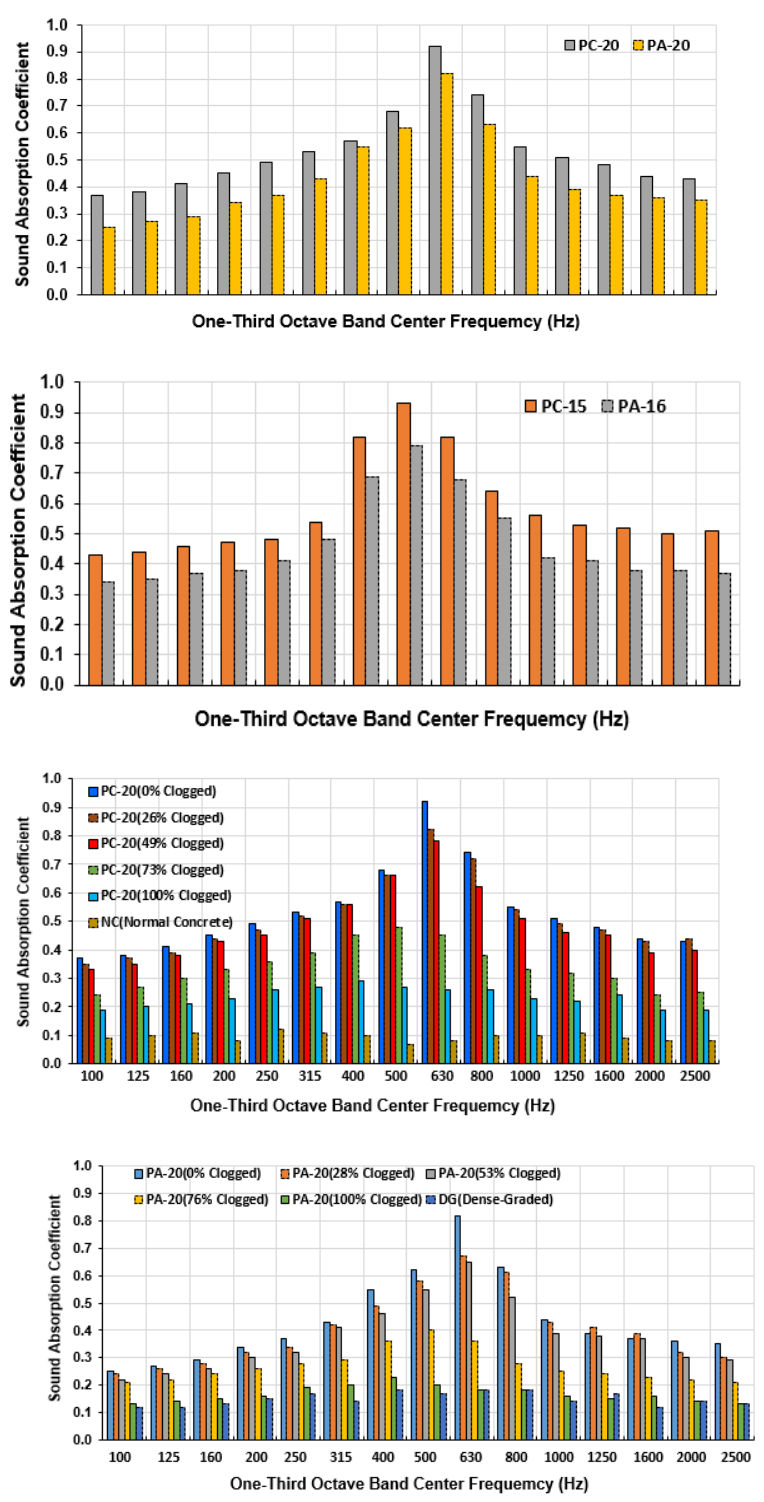

Fig. 6 Effect of clogging on sound absorption spectra of (a) PC and NC and (b) PA and DG asphalt.

\section{CONCLUSION}

The effect of clogging and porosity level on the sound absorption properties were studied in this paper. At a given porosity level, PC mixtures had better sound absorption capabilities than the PA mixtures. For both PA and PC mixtures, the sound absorption capabilities were heavily affected by clogging. At the same clogging percentage level, PC mixtures had better sound absorption performance than the PA mixtures. When the $100 \%$ clogged stage was reached, the sound absorption capability for PC still possessed higher performance than that of $\mathrm{NC}$, while PA mixtures had almost the same level of sound absorption capability as that of DG.

\section{REFERENCES}

11] T.F. Fwa, S.A. Tan and Y.K. Guwe, "Laboratory Evaluation of Clogging Potential of Porous Asphalt Mixtures," Transportation Research Record, No. 1681, pp. 43-49, 2002.
[2] T.F. Fwa, E. Lim and K. H. Tan, "Comparison of Permeability and Clogging Characteristics of Porous Asphalt and Pervious Concrete Pavement Materials," Transportation Research Record, No. 2511, pp.7280, 2015.

[3] T.F. Fwa, S. A. Tan, and C. T. Chuai, "Permeability Measurement of Base Materials Using Falling-Head Test Apparatus," Transportation News Record Number 1615, pp.94-99, 1998.

[4] S.A. Tan, T. F. Fwa and C. T. Chuai, "Automatic Field Permeameter for Drainage Properties of Porous Asphalt Mixes," Journal of Testing and Evaluation, Volume 27, Number 1, pp.57-62, 1999.

[5] C. Buratti and E. Moretti, "Traffic Noise Pollution: Spectra Characteristics and Windows Sound Insulation in Laboratory and Field Measurements," Journal of Environmental Science and Engineering, Vol. 4, No. 12, pp. 28-36, 2010.

[6] R.O. Rasmussen and R. C. Sohaney, "A Tire-Pavement and Environmental Traffic Noise Research Study," Report No. CDOT-20125. Colorado Department of Transportation, Denver, 2012. 